Revista Destaques Acadêmicos, Lajeado, v. 12, n. 3, 2020. ISSN 2176-3070

DOI: http://dx.doi.org/10.22410/issn.2176-3070.v12i3a2020.2677

http://www.univates.br/revistas

\title{
VIOLÊNCIA DOMÉSTICA CONTRA OS IDOSOS: UMA REVISÃO INTEGRATIVA
}

\author{
Bruna Isoppo da Silva ${ }^{1}$, Letícia Pilotto Casagranda Filgueiras², \\ Emily da Silva Eberhardt ${ }^{3}$, Atalíbio Felipe Becker Baltazar ${ }^{4}$
}

\begin{abstract}
Resumo: Introdução: A violência doméstica se destaca como um dos principais problemas de saúde pública, principalmente, em nosso país. Além de o tema ser pouco debatido, as produções científicas são escassas e os índices de violência estão aumentando cada dia mais. Objetivo: Analisar as produções bibliográficas acerca de idosos vítimas de violência doméstica, bem como caracterizar o perfil destes idosos, identificar os agressores e os principais tipos de violências sofridas. Métodos: Trata-se de um estudo de revisão integrativa da literatura, com pesquisas realizadas nas bases de dados BDenf, LILACS, SciELO, cujos artigos foram publicados no período de 2006 a 2016. Resultados: Evidenciou-se que as principais vítimas de maus-tratos na terceira idade são do sexo feminino, de 60 a 69 anos, analfabetas ou com baixa escolaridade, casadas e aposentadas. Como principal morbidade, destaca-se a Diabetes Mellitus, como principais agressores têm-se os cônjuges ou membros da família e o principal tipo de violência relatada, foi a psicológica. Conclusão: Com o aumento da população idosa, os prejuízos decorrentes da violência doméstica sofrida na terceira idade refletem diretamente em nosso cotidiano e está se tornando um grave problema de saúde pública. Ainda são escassos os estudos na área e as pesquisas pouco aprofundadas, tornandose necessário, maior atenção das políticas públicas, programas educacionais e atenção por parte das equipes de saúde, a fim de que estes idosos não continuem sendo alvo de maus-tratos no seu ambiente familiar.
\end{abstract}

Palavras-chave: Maus-tratos ao Idoso, violência doméstica, enfermagem.

1 Centro Universitário Cenecista de Osório.

2 Enfermeira. Doutoranda em Ciências ds Saúde pelo Programa de Pós Graduação da UFPEL. Docente do curso de enfermagem, do Centro Universitário Cenecista de Osório.

3 Centro Universitário Cenecista de Osório.

4 Centro Universitário Cenecista de Osório. 


\section{INTRODUÇÃO}

O envelhecimento populacional, antes, realidade demográfica apenas de países desenvolvidos, atualmente, está sendo característica também de países em desenvolvimento. O Instituto Brasileiro de Geografia e Estatística (IBGE) apontou, no censo de 2010, um percentual de 10,9\% de idosos na população brasileira. As projeções demográficas sugerem que em 2025 o Brasil terá a sexta maior população de idosos no mundo (IBGE, 2010; ALMEIDA et al, 2019).

O envelhecimento é uma das etapas da vida em que as pessoas estão sujeitas a passar por mudanças desde físicas, até psicológicas e sociais. Dados demonstram que houve uma queda na taxa de fecundidade e um aumento expressivo na expectativa de vida. Desta forma, vivencia-se uma mudança na estrutura etária, em que envelhecer é um processo natural, tornando-se frágeis, fazendo com que as condições de saúde possam ser agravantes, prejudicando a qualidade de vida (MAIA et al, 2019).

Em um país com intensas desigualdades sociais, este rápido crescimento da população idosa gera impacto epidemiológico, trazendo desafios importantes para o sistema de saúde. Surgem alterações no estilo de vida e problemas de saúde, além do processo fisiológico do próprio envelhecimento, como a perda da força muscular, aumentando assim o risco de quedas, diminuição do débito cardíaco, da frequência cardíaca, da capacidade vital, diminuição no número e tamanho dos neurônios, da frequência e volume respiratório e maior predominância de Doenças Crônicas Não-Transmissíveis (DCNT) (OLIVEIRA et al, 2018).

Devido a situações de mudança no perfil social e a facilidade de os idosos tornarem-se vulneráveis a determinadas patologias, muitos deles necessitam de cuidados no seu dia a dia, tornando-se, desta forma, expostos a situações de risco como a violência doméstica. A agressão contra a pessoa idosa é considerada um problema social grave e universal, que acomete todas as classes sociais, independente de status socioeconômico, etnia e religião (AZEVEDO; SILVA, 2019).

O artigo 19 da lei $n^{\circ} 10.741$, de $1^{\circ}$ de outubro de 2003, que dispõe sobre o Estatuto do Idoso, descreve violência contra o idoso como qualquer ação ou omissão praticada em local público e privado que cause morte, dano ou sofrimento físico ou psicológico à pessoa idosa. $\mathrm{O}$ mesmo artigo refere que os casos suspeitos ou confirmados de violência devem ser objeto de notificação compulsória (BRASIL, 2003).

O debate sobre o contexto da violência contra os idosos no Brasil é escasso, visto que as informações sobre doenças, lesões e traumas de causas violentas são pouco consistentes e subnotificadas. Nesse sentido, não há estatísticas comprovadas de quantos destes indivíduos são agredidos, nem suas possíveis causas. Isso porque a maioria dos idosos não denuncia nenhum tipo de violência, sendo elas físicas ou psicológicas (AZEVEDO; SILVA, 2019). 
A maioria dos casos de violência contra os idosos acontece no ambiente doméstico e é cometida por membros próximos. No âmbito familiar, as violências físicas e psicológicas confundem-se com o padrão de relacionamento, muitas vezes resultantes da sobrecarga que se constitui em um dos principais fatores de risco para violência contra idosos incapazes de realizar autocuidado (LINO et al, 2019).

No Brasil, a maioria dos idosos moram com seus familiares, sendo estes os principais cuidadores, e quanto maior a dependência, maior o grau de vulnerabilidade a violência doméstica (OLIVEIRA et al, 2018). Conforme a legislação brasileira, os familiares são responsáveis pelos cuidados aos idosos, que em sua maioria são indivíduos extremamente frágeis (BRASIL, 2003).

A violência no ambiente intrafamiliar geralmente é silenciada e não discriminada por envolver relações e sentimento de insegurança, medo, conflitos familiares, culpa, afetividade e relações de dependência entre o idoso e o cuidador, resultando em omissão e aceitação, em que a vítima tenta entender as atitudes do agressor como um acontecimento natural entre os membros da família. Estes sentimentos levam os idosos, muitas vezes já fragilizados, a não denunciarem as agressões, como uma forma de evitar novos atos de violência (AZEVEDO; SILVA, 2019).

A violência doméstica contra idosos tem se destacado como um dos principais problemas de saúde pública, causando adoecimento físico, psíquicos, podendo levar a morte. Além de ser um tema pouco debatido, as produções científicas são escassas e os índices de violência estão aumentando cada dia mais. $\mathrm{O}$ acolhimento, respeito, sigilo e a segurança devem sempre ser priorizados no atendimento ao idoso, sendo que este em sua maioria, ao ser vítima de algum tipo de violência, prefere não se dirigir aos serviços de saúde, visto que sustentam o silêncio (MAIA et al, 2019).

Visando à minimização da violência doméstica contra a pessoa idosa, a realização desta pesquisa poderá contribuir acerca do levantamento de estudos que existam contra este tipo de ato que acomete a terceira idade. Neste contexto, o objetivo do estudo é caracterizar quem são estas vítimas, identificar os agressores e os principais tipos de violência sofrida, conforme produções bibliográficas publicadas no período de 2006 a 2016, a fim de atualizar os profissionais de Enfermagem sobre o olhar que devem ter ao seu paciente na assistência, muito além daquilo que é objetivo, assim contribuindo para a denúncia dos agressores que por muitas vezes podem estar na casa das vítimas.

\section{METODOLOGIA}

Trata-se de uma revisão integrativa com abordagem quantitativa, em que se busca alcançar o objetivo proposto, permitindo assim uma síntese de conhecimento sobre determinado assunto. Desta forma, abrem-se portas para o entendimento e a realização de novos estudos, o estudante passa a ter um olhar 
mais criterioso, melhorando suas práticas clínicas e contribuindo para suas tomadas de decisão. Além disso, esta síntese permite que novas conclusões sejam discutidas sobre os temas abordados (POLIT, 2006).

Procurando contribuir para a prevenção de novos casos de violência e suprir a necessidade de discussão sobre a temática de maus-tratos aos idosos, criou-se com este estudo, a seguinte pergunta norteadora: Quais são os idosos que sofreram violência doméstica no Brasil no período de 2006 a 2016?

Para atingir o objetivo proposto desta revisão, elencaram-se as respectivas etapas: Identificação do tema; estabelecimento de critérios para inclusão e exclusão; avaliação dos estudos incluídos; interpretação e síntese de resultados. Como critérios de inclusão, utilizou-se artigos de abordagem quantitativa, que responderam ao objetivo do presente estudo, publicados no período 2006 a 2016 e de exclusão, artigos de revisão bibliográfica, integrativa, narrativa e sistemática, estudos de caso; também não foram utilizados artigos que não estavam liberados na íntegra.

Com a definição da temática, partiu-se para a escolha dos descritores, os quais respondessem ao objetivo do estudo. Neste contexto, escolheu-se: MausTratos ao Idoso (Elder Abuse), Enfermagem (Nursing), Violência Doméstica (Domestic Violence), previamente consultados nos descritores em ciências da saúde (DeCS) e no Medical Subject Headings (Mesh). Para o cruzamento de dados utilizou-se o operador boleano And. Os estudos foram pesquisados na internet, nas bases de dados Scientific Electronic Library Online (SciELO), Literatura Latino-Americana em Ciências de Saúde (LILACS) e na Base de Dados Bibliográficos Especializada na Área de Enfermagem do Brasil (BDEnf), conforme no Quadro 1: 
QUADRO 1: Representação do cruzamento dos descritores.

\begin{tabular}{|c|c|c|c|c|c|}
\hline DeSC & $\begin{array}{c}\text { Maus-Tratos } \\
\text { ao idoso } \\
\text { AND } \\
\text { Violência } \\
\text { doméstica } \\
\text { AND } \\
\begin{array}{c}\text { Bases de } \\
\text { Dados }\end{array}\end{array}$ & $\begin{array}{c}\text { Maus- } \\
\text { Tratos ao } \\
\text { Idoso } \\
\text { AND } \\
\text { Violência } \\
\text { Doméstica }\end{array}$ & $\begin{array}{c}\text { Maus-Tratos } \\
\text { ao Idoso } \\
\text { AND } \\
\text { Enfermagem }\end{array}$ & $\begin{array}{c}\text { Enfermagem } \\
\text { AND } \\
\text { Violência } \\
\text { Doméstica }\end{array}$ & TOTAL \\
\hline SCIELO & 0 & 11 & 3 & 78 & 92 \\
\hline LILACS & 1 & 36 & 7 & 90 & 134 \\
\hline BDENF & 1 & 6 & 3 & 54 & 64 \\
\hline TOTAL & 2 & 53 & 13 & 222 & 290 \\
\hline
\end{tabular}

Fonte: SILVA et al, 2017.

Para a análise dos estudos encontrados, optou-se para a realização de um Fluxograma, no qual está descrito os artigos encontrados, selecionados e excluídos da pesquisa, conforme Figura 1. 
FIGURA 1- Fluxograma de revisão nas bases de dados científicos nos cruzamentos dos descritores em português

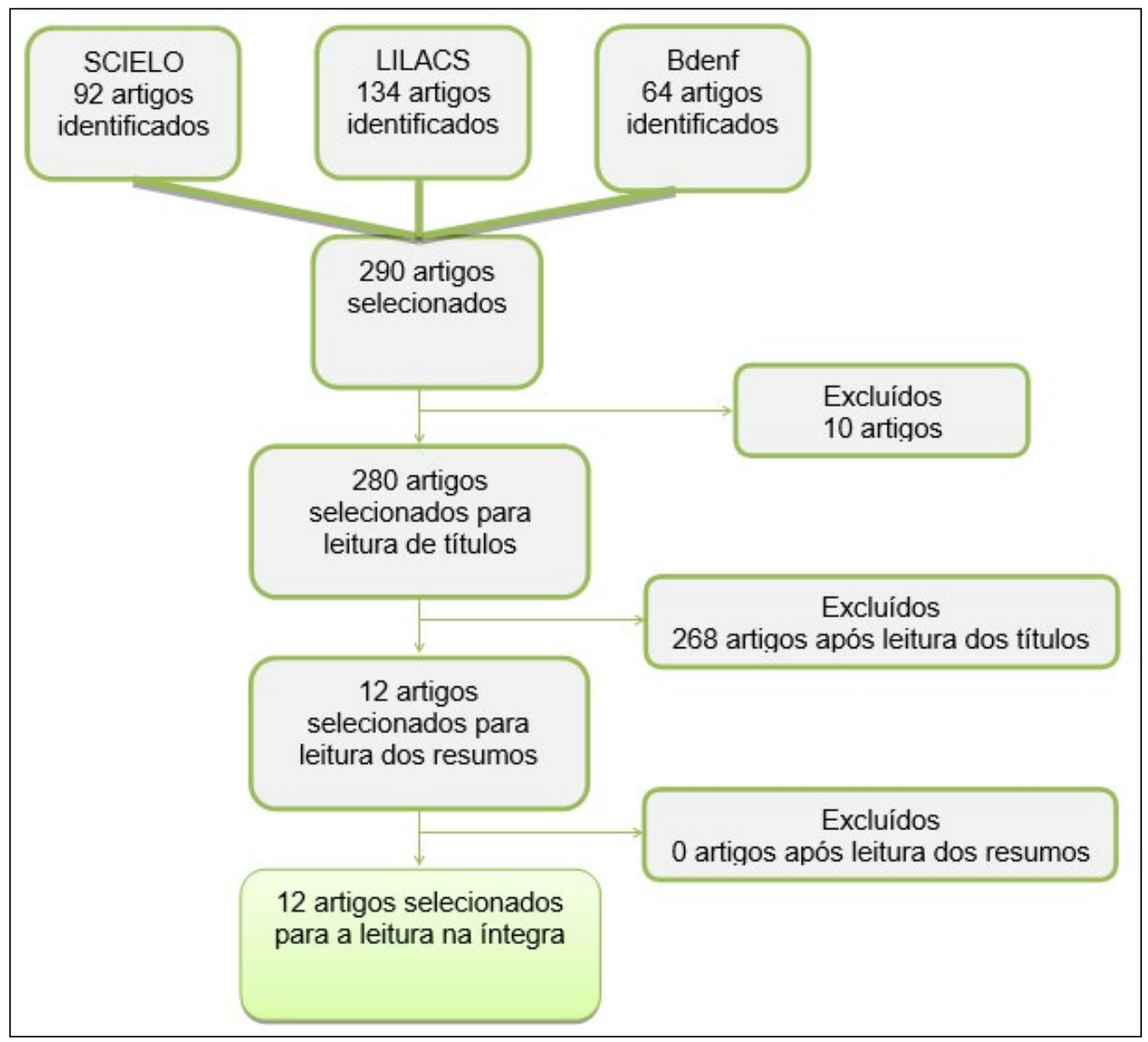

Fonte: SILVA et al, 2017.

Considerando-se os princípios éticos, todas as produções utilizadas nesta revisão integrativa foram devidamente referenciadas conforme as normas da Associação Brasileira de Normas Técnicas (ABNT).

\section{RESULTADOS E DISCUSSÕES}

Os 12 artigos selecionados para esta revisão integrativa, sobre os maustratos contra os idosos, colaboraram para atualizar os estudos sobre a violência doméstica na terceira idade; encontram-se nas seguintes bases de dados SciELO, LILACS e BDEnf; no período de 2006 a 2016, conforme-se observa-se abaixo: 
QUADRO 2: Relação de publicações cientificas, de acordo com a caracterização do título, autores, revista, ano, país e fonte. Osório/Rio Grande do Sul, Brasil, 2017.

\begin{tabular}{|c|c|c|c|c|c|}
\hline TÍTULO & AUTORES & REVISTA & ANO & PAÍS & FONTE \\
\hline $\begin{array}{l}\text { Prevalência de violência } \\
\text { contra idosos e fatores } \\
\text { associados, estudo de } \\
\text { base populacional em } \\
\text { Florianópolis, SC }\end{array}$ & $\begin{array}{l}\text { BOLSONI, Carolina Carvalho; } \\
\text { COELHO, Elza Berger Salema; } \\
\text { GIEHL, Maruí Weber Corseuil y } \\
\text { D'ORSI, Eleonora. }\end{array}$ & 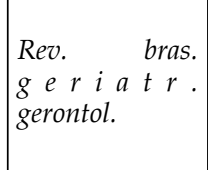 & 2016 & Brasil & Scielo \\
\hline $\begin{array}{l}\text { Características dos idosos } \\
\text { vítimas de } \\
\text { doméstica no nolência } \\
\text { Federal }\end{array}$ & $\begin{array}{l}\text { OLIVEIRA, Maria Liz Cunha de; } \\
\text { GOMES, Ana Cláudia Gonçalves; } \\
\text { AMARAL, Cláudia Pereira Machado } \\
\text { and SANTOS, Laysa Buriti dos }\end{array}$ & 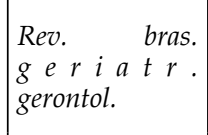 & 2012 & Brasil & Scielo \\
\hline $\begin{array}{l}\text { Ocorrência de maus- } \\
\text { tratos em idosos no } \\
\text { domicílio }\end{array}$ & $\begin{array}{l}\text { GAIOLI, Cheila Cristina Leonardo } \\
\text { de Oliveira e RODRIGUES, Rosalina } \\
\text { Aparecida Partezani. }\end{array}$ & $\begin{array}{l}R \quad e \quad v \\
\text { Latino-Am. } \\
\text { Enfermagem }\end{array}$ & 2008 & Brasil & Scielo \\
\hline \begin{tabular}{lc|}
$\begin{array}{l}\text { Fatores } \\
\text { violência }\end{array}$ & associados à \\
contra a pessoa idosa
\end{tabular} & $\begin{array}{l}\text { ABATH, Marcella de Brito; LEAL, } \\
\text { Márcia Carréra Campos and MELO } \\
\text { FILHO, Djalma Agripino de. }\end{array}$ & 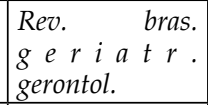 & 2012 & Brasil & Scielo \\
\hline $\begin{array}{l}\text { Rompendo o silêncio } \\
\text { e suas barreiras: um } \\
\text { inquérito domiciliar sobre } \\
\text { a violência doméstica } \\
\text { contra idosos em área de } \\
\text { abrangência do programa } \\
\text { médico de família de } \\
\text { Niterói - RJ/ Brasil }\end{array}$ & $\begin{array}{l}\text { MORAES, Claudia Leite de; } \\
\text { APRATTO JUNIOR, Paulo } \\
\text { Cavalcante and REICHENHEIM, } \\
\text { Michael Eduardo. }\end{array}$ & $\begin{array}{l}\text { Cad. } \\
\text { Pública }\end{array}$ & 2008 & Brasil & Scielo \\
\hline $\begin{array}{l}\text { Violência Física e e } \\
\text { psicológica contra idosos: } \\
\text { Prevalência e fatores } \\
\text { associados }\end{array}$ & $\begin{array}{l}\text { PAIVA, Mariana Mapelli de; } \\
\text { TAVARES, Darlene Mara dos Santos. }\end{array}$ & $\begin{array}{l}\text { Rev. } \\
\text { Enferm. }\end{array}$ & 2015 & Brasil & Scielo \\
\hline $\begin{array}{l}\text { Capacidade funcional e } \\
\text { situações de violência em } \\
\text { idosos }\end{array}$ & $\begin{array}{l}\text { FAUSTINO, Andréa Mathes; } \\
\text { GANDOLFI, Lenora and MOURA, } \\
\text { Leides Barroso de Azeved }\end{array}$ & $\begin{array}{l}\text { Acta paul. } \\
\text { enferm. }\end{array}$ & 2014 & Brasil & Scielo \\
\hline $\begin{array}{l}\text { Violência contra idosos: } \\
\text { descrição de casos no } \\
\text { município de Aracajú- } \\
\text { Sergipe, Brasil }\end{array}$ & $\begin{array}{l}\text { AGUIAR, Maria Pontes Campos } \\
\text { de, LEITE, Heloiza Andrade, DIAS, } \\
\text { Iris Melo, MATTOS, Maria Claudia } \\
\text { Tavares de, LIMA, Wilma Resende. } \\
\end{array}$ & $\begin{array}{l}\text { Escola } \\
\text { Nery }\end{array}$ & 2015 & Brasil & LILACS \\
\hline $\begin{array}{l}\text { Manifestaciones de } \\
\text { violencia intrafamiliar } \\
\text { hacia adultos mayores } \\
\text { diabéticos. }\end{array}$ & $\begin{array}{l}\text { CASANOVA MORENO, María de la } \\
\text { Caridad, TRASANCOS DELGADO, } \\
\text { Maricela, CORVEA COLLAZO, } \\
\text { Yariet, Pérez Sierra, MAYRA, \& } \\
\text { PRATS ÁLVAREZ, Olga María } \\
\end{array}$ & $\begin{array}{l}\text { Rev Cubana } \\
\text { Med Gen Integr }\end{array}$ & 2013 & Cuba & LILACS \\
\hline $\begin{array}{l}\text { Comportamento de la } \\
\text { violência intrafamiliar en } \\
\text { el adulto mayor }\end{array}$ & \begin{tabular}{|lrr} 
DOCAMPO & SANTALO, & Lourdes; \\
BARRETO r & LACABA, rita; \\
SANTANA SERRANO, Caridad.
\end{tabular} & $A M C$ & 2009 & Cuba & LILACS \\
\hline $\begin{array}{l}\text { Caracterização da pessoa } \\
\text { idosa vítima de violência }\end{array}$ & 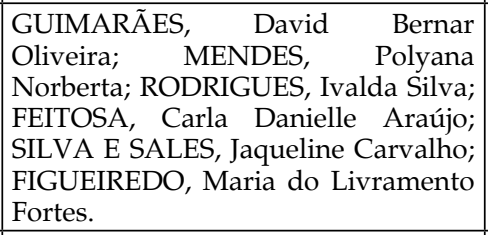 & Rev Enferm. & 2016 & Brasil & BDENF \\
\hline $\begin{array}{l}\text { Vivência de situação de } \\
\text { violência contra idosos }\end{array}$ & $\begin{array}{l}\text { ALENCAR, Kelly Cristina de } \\
\text { Albuquerque; SANTOS, Jaqueline de } \\
\text { Oliveira; HINO, Paula. }\end{array}$ & $\begin{array}{l}\text { Rev. enferm. } \\
\text { atenção saúde }\end{array}$ & 2014 & Brasil & BDENF \\
\hline
\end{tabular}

Fonte: SILVA, 2017. 
Constatou-se que no período delimitado foram publicados 12 artigos com enfoque quantitativos sobre maus-tratos contra os idosos. Dos artigos encontrados, 10 (83\%) são brasileiros e dois (16,6\%) são cubanos.

Ao caracterizar as vítimas quanto ao sexo, 10 (83\%) dos estudos verificaram que as principais vítimas de maus-tratos são mulheres (BOLSONI et al, 2016; ABATH; LEAL; MELO FILHO, 2012; MORAES et al, 2008; PAIVA; TAVARES, 2015; FAUSTINO; GANDOLFI; MOURA, 2014; AGUIAR et al, 2015; CASANOVA MORENO; et al, 2013; DOCAMPO SANTALO; BARRETO LACABA; SANTANA SERRANO, 2009; GUIMARÃES et al, 2016; ALENCAR; SANTOS; HINO, 2014). Já os outros dois estudos $(16,6 \%)$ verificaram que os idosos mais agredidos são os homens (OLIVEIRA; et al, 2012; GAIOLI; RODRIGUES, 2008).

Para Faustino; Gandolfi; Moura, 2014, um dos motivos das mulheres serem maiores vítimas de violência doméstica na terceira idade se dá pela feminização desta população devido a sua longevidade. As mulheres são mais cuidadosas, atentas com a saúde e se expõe menos a riscos enquanto jovens, assim a expectativa de vida delas chega a ser cerca de 8 a 10 anos maior que a dos homens.

As questões históricas de gênero também influenciam, pois, existem hierarquias rígidas entre os papeis do homem e da mulher na sociedade, a cultura ainda está enraizada no nosso cotidiano na qual há uma discriminação contra as mulheres (SANCHES, 2006; NOGUEIRA; FREITAS; ALMEIDA, 2011).

Ao evidenciar a idade destes idosos agredidos, quatro $(33,3 \%)$ dos estudos encontram-se em comum acordo para os maiores casos de violência ocorrerem na faixa de 60 a 69 anos (BOLSONI et al., 2016; GAIOLI; RODRIGUES, 2008; FAUSTINO; GANDOLFI; MOURA, 2014; AGUIAR et al, 2015; ALENCAR; SANTOS; HINO, 2014).

Um dos fatos que podem explicar por que a maioria dos idosos que sofreram violência doméstica encontrava-se nesta faixa etária é o fato de que, esta é a idade em que os idosos conquistam o direito a aposentadoria. Sendo assim, acabam ficando mais tempo em casa, muitas vezes dependentes dos familiares para executar suas atividades básicas diárias, ficando mais propensos a sofrer maus-tratos (AGUIAR et al, 2015).

Ainda, em análise dos estudos, sete (58,3\%) dos artigos demonstraram analfabetismo ou baixa escolaridade dos idosos que sofreram algum tipo de violência (BOLSONI et al, 2016; MORAES; APRATTO JUNIOR; REICHENHEIM, 2008; FAUSTINO; GANDOLFI; MOURA, 2014; AGUIAR et $a l, 2015$; DOCAMPO SANTALO; BARRETO LACABA; SANTANA SERRANO, 2009; GUIMARÃES et al, 2016; ALENCAR; SANTOS; HINO, 2014).

A baixa escolaridade ou analfabetismo, segundo Baptista (2007), aumenta as chances de os idosos sofrerem violência doméstica, devido as dificuldades 
de acesso à informação e leitura, prejudicam o idoso para fins de denúncia e resolução de problemas relacionados a saúde, segurança e educação.

Sobre o estado civil destes idosos, seis (50\%) dos estudos apontaram que os agredidos são casados ou possuem um companheiro (OLIVEIRA et al, 2012; GAIOLI; RODRIGUES, 2008; MORAES; APRATTO JUNIOR; REICHENHEIM, 2008; PAIVA; TAVARES, 2015; FAUSTINO; GANDOLFI; MOURA, 2014; ALENCAR; SANTOS; HINO, 2014). Outros três estudos (25\%), verificaram que os idosos mais agredidos eram solteiros, divorciados ou viúvos (BOLSONI; COELHO; GIEHL; D’ORSI, 2016; ABATH; LEAL; MELO FILHO, 2012; GUIMARÃES et al., 2016).

Para D'oliveira et al (2009), a violência praticada por cônjuges está relacionada ao fato de o homem sentir-se no direito de controlar seus bens e condutas. A dependência afetiva também é citada pelos autores Sanches; Lebrão; Duarte (2008).

Ao evidenciar a renda das vítimas, quatro $(33,3 \%)$ dos estudos relataram que os idosos são aposentados (ABATH; LEAL; MELO FILHO, 2012; MORAES; APRATTO JUNIOR; REICHENHEIM, 2008; AGUIAR et al., 2015; GUIMARÃES et al., 2016).

Os autores Abath; Leal; Melo Filho (2012) e Aguiar et al. (2015) relacionaram o fato de os idosos serem aposentados e sofrerem violência doméstica com mais frequência por passarem mais tempo em casa. Eles ainda citam a aposentadoria como fonte econômica do lar, levando a violências do tipo financeira, psicológica e física, ou ainda dependência para as atividades do lar por parte dos aposentados, consequentemente causando incômodo e irritação por parte dos seus cuidadores.

Poucos estudos discutiram sobre as morbidades que atingem os idosos, vítima de violência doméstica, apenas 33,3\% autores trouxeram sobre o assunto, em que a Diabetes Mellitus aparece em $25 \%$ dos estudos, sendo ela a principal morbidade nos estudos dos autores Moraes; Apratto Junior; Reichenheim (2008); e Guimarães et al. (2016). Em segundo lugar, a Hipertensão Arterial é a apontada pelo autor Faustino; Gandolfi; Moura (2014) e as doenças articulares aparecem na terceira colocação, citada pelo autor Paiva; Tavares (2015).

Em um estudo de Santos; Griep (2011), eles demonstraram que diferentemente do homem, as mulheres possuem menos capacidade funcional na terceira idade, maiores riscos a DCNT e maiores riscos para hospitalização. Corroborando com este fato, Faustino; Gandolfi; Moura (2014) afirmam que quanto maior for a dependência que o idoso tem de manter suas atividades diárias básicas, maiores serão as chances que eles tem de sofrer violência, o que explica a dependência do gênero ser mais agravante.

Desta forma, verificou-se que são necessários estudos aprofundados nas áreas das morbidades dos idosos vítimas de violência doméstica por ser 
também um indicador de maus-tratos, já que estas doenças acarretam maior cuidado e dependência, sendo ela grave ou moderada.

Quanto aos principais agressores dos idosos, 58,3\% dos estudos, revelaram que os cônjuges, filhos, netos ou outros membros da família são os principais praticantes de agressão contra esta faixa etária (BOLSONI et al., 2016; GAIOLI; RODRIGUES, 2008; MORAES; APRATTO JUNIOR; REICHENHEIM, 2008; PAIVA; TAVARES, 2015; AGUIAR et al, 2015; CASANOVA MORENO et al., 2013; ALENCAR; SANTOS; HINO, 2014).

A pesquisa de Aguiar et al., (2015) evidenciou o perfil dos agressores de idosos, mostrando respectivamente a vulnerabilidade e os fatores de risco que envolvem as vítimas de violência doméstica. Ainda, o agressor geralmente vive na mesma residência que as vítimas. Um dos fatos que podem suceder essa agressividade é a questão de as vítimas dependerem financeiramente de sua família, como também precisarem de apoio para realizarem suas atividades diárias básicas. São também fatores de risco o abuso de álcool e drogas praticado por algum membro da família ou ainda pela própria vítima, o isolamento social do idoso e o histórico de violência doméstica com algum dos membros da família.

Ao averiguar quais são as principais violências domésticas contra os idosos descritas nos estudos, $50 \%$ deles referiu que a violência psicológica foi a mais acometida pelos agredidos (BOLSONI et al., 2016; PAIVA; TAVARES, 2015; FAUSTINO; GANDOLFI; MOURA, 2014; AGUIAR et al, 2015; CASANOVA MORENO; et al, 2013; GUIMARÃES et al., 2016). Outros $41,6 \%$ dos estudos apontaram que foi a violência física (OLIVEIRA et al., 2012; GAIOLI; RODRIGUES, 2008; ABATH; LEAL; MELO FILHO, 2012; MORAES; APRATTO JUNIOR; REICHENHEIM, 2008; ALENCAR; SANTOS; HINO, 2014). E, apenas um $(8,3 \%)$ estudo, aponta a negligência como a principal violência sofrida por pessoas da terceira idade (DOCAMPO SANTALO; BARRETO LACABA; SANTANA SERRANO, 2009).

A violência psicológica se encontra como a mais praticada; seguida da violência física, devido ao fato de que antes de ocorrer qualquer tipo de agressão, existe uma ameaça por parte do agressor. Neste contexto, formase um ciclo de violência, que por muitas vezes é negligenciada no ambiente familiar (PAIVA; TAVARES, 2015).

Além disso, a violência psicológica aumenta a possibilidade de que as vítimas sofram outros tipos de violência, ela coloca o idoso frente a situações de medo e faz com que eles se sintam humilhados. Desta forma, os idosos ficam acuados e vulneráveis para outros tipos de abusos (BOLSONI et al., 2016).

Quando verificado a forma em que estes idosos foram acometidos, $16,6 \%$ dos estudos trouxeram que eles sofreram ferimentos nas regiões do tronco e membros superiores (GAIOLI; RODRIGUES, 2008; ABATH; LEAL; MELO FILHO, 2012). Neste contexto, evidencia-se que a causa destas regiões 
do corpo serem mais atingidas é a tentativa de defesa por parte dos agredidos (ABATH; LEAL; MELO FILHO, 2012).

Os maus-tratos contra a pessoa idosa precisam ser debatidos com mais ênfase no cenário atual. Com o aumento da população idosa, os prejuízos decorrentes da violência doméstica sofrida na terceira idade refletem diretamente em nosso cotidiano e está cada vez mais se tornando um grave problema de saúde pública.

\section{CONSIDERAÇÕES FINAIS}

Ao longo deste trabalho procurou-se contribuir para a prevenção de novos casos de violência, identificando as vítimas e tornando mais fácil a abordagem delas. Procurou-se também, suprir a necessidade de discussão sobre a temática de maus-tratos aos idosos e caracterizar o perfil das vítimas no período dos anos de 2006 a 2016.

Ao analisar os estudos quantificados e publicados, identificou-se que as vítimas de maus-tratos na terceira idade são em sua maioria do gênero feminino, na faixa etária de 60 a 69 anos, com baixa escolaridade ou analfabetos, casados e aposentados.

Dentre as morbidades das vítimas que mais são agredidas, compreendem Hipertensão Arterial, Diabetes Mellitus e Doenças Articulares, respectivamente. Ao identificar quais são os principais agressores destes idosos, evidenciou-se que são cônjuges, filhos, netos ou ainda membros da família que residem na mesma casa.

O principal tipo de violência sofrida pelos idosos é a violência psicológica, seguida de violência física e negligência. Não desconsiderando que os outros tipos de violência também são comumente relatados e denunciados nos casos de maus-tratos. Os resultados deste estudo colaboram para atualização do perfil das vítimas que estão sendo agredidas nos ambientes familiares da atualidade, mas não são suficientes para caracterizar a dimensão que é esta problemática.

Ainda são escassos os estudos na área e as pesquisas pouco aprofundadas, torna-se necessário maior atenção das políticas públicas, programas educacionais e atenção por parte das equipes de saúde, a fim de que estes idosos não continuem sendo alvo de maus-tratos no seu ambiente familiar. Estas vítimas ao chegarem ao serviço de saúde, podem ser facilmente identificadas. Cabe ao profissional enfermeiro o acolhimento, e transmitir segurança frente ao que o idoso relata e apresenta, conhecendo desta forma o perfil e identificando os sinais de violência, logo se é possível chegar ao alvo, e poder afastar o agressor por meio de denúncias a estes atos. 


\section{REFERÊNCIAS}

ABATH, Marcella de Brito; LEAL, Márcia Carréra Campos; MELO FILHO, Djalma Agripino de. Fatores associados à violência doméstica contra a pessoa idosa. Rev. bras. geriatr. gerontol., Rio de Janeiro, v. 15, n. 2, p. 305-314, 2012.

AGUIAR, Maria Pontes Campos de. Violência contra idosos: descrição de casos no Município de Aracaju, Sergipe, Brasil. Esc. Anna Nery, Rio de Janeiro, v. 19, n. 2, p. 343-349, June 2015.

ALENCAR, Kelly Cristina de Albuquerque; SANTOS, Jaqueline de Oliveira; HINO, Paula. Vivência de situação de violência contra idosos, Rev. enferm. atenção saúde, v. 3, n. 1, p. 74-83, 2014.

ALMEIDA, Camila Aparecida Pinheiro Landim et al. Aspectos Relacionados à Violência Contra o Idoso: Concepção do Enfermeiro da Estratégia Saúde da Família. J. res.: fundam. care. online 2019. 11(n. esp): 404-410.

ARGÔLO, Diêgo Edington; FURTADO, Natália Maria Reis Oliveira. Dispositivos legais e efetivação dos direitos do idoso no Município de Itabuna, Ba.

Disponível em:<http:/ / periodicos.uesc.br/index.php/memorialidades/article/ download/128/144.>. Acesso em: 19 abr. 2017.

AZEVEDO, Caterine Oliveira; SILVA, Thiago Augusto Soares Monteiro da. Cuidados de Enfermagem para detecção de violência contra idosos. Revista Pró-UniverSUS. 2019 Jan./Jun.; 10 (1): 55-59.

BAPTISTA, Makilin Nunes. Suporte familiar e violência. In ipsi: Romaro, $R$. Aparecida; Capitão, Cláudio Gárcia (Org.). As faces da violência: aproximações, pesquisas e reflexões. São Paulo: Vetor, 2007, p. 11-31.

BOLSONI, Carolina Carvalho. Prevalência de violência contra idosos e fatores associados, estudo de base populacional em Florianópolis, SC. Rev. bras. geriatr. gerontol., Rio de Janeiro, v. 19, n. 4, p. 671-682, agosto, 2016.

BRASIL. Constituição (1988). Constituição da República Federativa do Brasil, promulgada em 8 de outubro de 1988. Planalto, DF. Disponível em: $<$ http:/ /www. planalto.gov.br/ccivil_03/Constituicao/Constitui\%C3\%A7ao.htm>. Acesso em: 12 jun. 2017.

BRASIL. Ministério da Saúde. Diretrizes e recomendações para o cuidado integral de doenças crônicas não transmissíveis: promoção de saúde, vigilância, prevenção e assistência, 2008. Pacto pela saúde, vol. 08. Disponível em:<http:/ /bvsms.saude. gov.br/bvs/publicacoes/diretrizes_recomendacoes_cuidado_doencas_cronicas.pdf >. Acesso em: 12 jun. 2017.

BRASIL. Ministério da Saúde. Lei Federal n 10. 741, de $1^{\circ}$ de outubro de 2003, que dispõe sobre o estatuto do idoso e dá outras providências. Planalto, DF. Disponível 
em:<http://www.planalto.gov.br/ccivil_03/leis/2003/L10.741.htm>. Acesso em: 21 jan 2020 .

BRASIL. Ministério da Saúde. Política nacional de redução de morbimortalidade por acidentes e violência. Planalto, DF: O Ministério; 2002. Disponível em:<http:/ /bvsms. saude.gov.br/bvs/publicacoes/acidentes.pdf>. Acesso em: 12 abr. 2017.

BRASL. Instituto Brasileiro de Geografia e Estatística (IBGE). Resultados do Censo 2010. Rio de Janeiro; 2010. Disponível em: <http:/ / www.censo2010.ibge.gov.br/ resultados_do_censo2010.php>. Acesso em: 21 jan 2020.

CASANOVA MORENO, María de la Caridad. Manifestaciones de violencia intrafamiliar hacia adultos mayores diabéticos. Pinar del Rio, 2012. Rev Cubana Med Gen Integr, Ciudad de La Habana, v. 29, n. 2, p. 160-172, jun. 2013

DOCAMPO SANTALO, Lourdes; BARRETO LACABA, Rita; SANTANA SERRANO, Caridad. Comportamiento de la violencia intrafamiliar en el adulto mayor. AMC, Camagüey, v. 13, n. 6, dic. 2009.

D'OLIVEIRA, Ana Flávia Pires Lucas. Fatores associados à violência por parceiro íntimo em mulheres brasileiras. Rev. Saúde Pública, São Paulo, v. 43, n. 2, p. 299-311, Apr. 2009. Disponível em:<http://www.scielo.br/scielo.php?script=sci arttext\&pid=S0034-89102009000200011\&lng=en\&nrm=iso $>$. Acesso em: 08 abr. 2017.

FALEIROS, Vicente de Paula. Violência contra a pessoa idosa: ocorrências, vítimas e agressores. Brasília, DF, Universa, 2007.

FAUSTINO, Andréa Mathes; GANDOLFI, Lenora; MOURA, Leides Barroso de Azevedo. Capacidade funcional e situações de violência em idosos. Acta paul. enferm., São Paulo, v. 27, n. 5, p. 392-398, Oct. 2014.

GAIOLI, Cheila Cristina Leonardo de Oliveira; RODRIGUES, Rosalina Aparecida Partezani. Ocorrência de maus-tratos em idosos no domicílio. Rev. Latino-Am. Enfermagem, Ribeirão Preto, v. 16, n. 3, p. 465-470, June 2008.

GUIMARÃES, David Bernar Oliveira. Caracterização da pessoa idosa vitima de violência, Rev. Enferm. UFPE online. Recife, v. 10, n. 3, p. 1343-50, 2016.

IBGE. Anuário Estatístico. Gov. Rio de Janeiro: IBGE; 2000. Disponível em:<http:/ / biblioteca.ibge.gov.br/visualizacao/periodicos/20/aeb_2000.pdf >. Acesso em: 12 abr. 2017.

IBGE. Síntese de indicadores sociais: uma análise das condições de vida. Rio de Janeiro, 2010.

KRUG, Etienne G Krug; MERCY, James A; DAHLBERG, Linda L; ZWI, Anthony B. World report on violence and health. Geneva: World Health Organization; 2002. 
LINO, Valéria Teresa Saraiva et al. Prevalência e fatores associados ao abuso de cuidadores contra idosos dependentes: a face oculta da violência familiar. Ciência \& Saúde Coletiva, 24(1):87-96, 2019.

MAIA, Paulo Henrique Silva et al. A ocorrência da violência em idosos e seus fatores associados. Rev Bras Enferm. 2019;72(Suppl 2):71-7.

MEIRA, Ednéia Campos. A violência ao idoso no contexto familiar. Memorialidades. Ilhéus, BA, Ano 1, n.2, p 33, jul./ dez. 2004.

MENDES, Márcia Regina Silvério Santana Barbosa. “O cuidado com os pés do senescente: um processo em construção." Florianópolis: Universidade Federal de Santa Catarina; (2000).

MENEZES, Maria do Rosario. Da violência revelada à violência silenciada: um estudo etnográfico sobre a violência doméstica contra o idoso [tese de doutorado em Enfermagem]. Ribeirão Preto (SP): Escola de Enfermagem/USP; 1999.

MINAYO, Maria Cecília de Souza.; COIMBRA Jr., Carlos E.A. (orgs.). Antropologia, Saúde e Envelhecimento. Rio de Janeiro: FIOCRUZ, 2002.

MINAYO, Maria Cecília de Souza. A inclusão da violência na agenda da saúde: trajetória histórica. Ciênc. saúde coletiva, Rio de Janeiro, v. 11, supl. p. 1259-1267, 2006. Disponível em:<http:/ /www.scielo.br/scielo.php?script=sci_arttext\&pid=S141381232006000500015\&lng=en\&nrm=iso >. Acesso em: 12 abr. 2017.

MINAYO, Maria Cecília de Souza. Violência contra idosos: o avesso do respeito à experiência e à sabedoria. Brasília: Secretaria Especial dos Direitos Humanos, $2^{\circ}$ edição, 2005.

MINAYO, Maria Cecília de Souza. Violência contra idosos: relevância para um velho problema. Cadernos de Saúde Pública, Rio de Janeiro, v. 19, n. 3, p. 783-791, 2003.

MINAYO, Maria Cecília de Souza. Violência: um velho-novo desafio para a atenção à saúde. Revista Brasileira de Educação Médica, Rio de Janeiro, v. 29, n. 1, p. 55-63, jan./ abr. 2005.

MORAES, Claudia Leite de; APRATTO JUNIOR, Paulo Cavalcante; REICHENHEIM, Michael Eduardo. Rompendo o silêncio e suas barreiras: um inquérito domiciliar sobre a violência doméstica contra idosos em área de abrangência do Programa Médico de Família de Niterói, Rio de Janeiro, Brasil. Cad. Saúde Pública, Rio de Janeiro, v. 24, n. 10, p. 2289-2300, Oct. 2008.

NASRI, Fabio. O envelhecimento populacional no Brasil. Einstein, v.6, supl.1, p.4-6, 2008. Disponível em:<http://www.prattein.com.br/home/images/stories/ Envelhecimento/envelhecimento_po pu.pdf>. Acesso em: 09 abr. 2017. 
NETTO, Matheus Papaléo. O estudo da velhice no século XX: histórico, definição do campo e temas básicos. Tratado de Geriatria e Gerontologia. Rio de Janeiro: Guanabara Koogan, p.1-12, 2002.

NOGUEIRA, Caroline Furtado; FREITAS, Maria Célia de; ALMEIDA, Paulo César de. Violência contra idosos no município de Fortaleza, CE: uma análise documental. Rev. bras. geriatr. gerontol., Rio de Janeiro, v. 14, n. 3, p. 543-554, 2011. Available from <http:/ / www.scielo.br/scielo.php?script=sci_arttext\&pid=S180998232011000300014\&lng=en\&nrm=iso $>$

OLIVEIRA, Annelissa Andrade Virgínio. Maus-tratos a idosos: revisão integrativa da literatura. Rev. bras. enferm., Brasília, v. 66, n. 1, p. 128-133, Feb. 2013. Disponível em:<http:/ /www.scielo.br/scielo. php?script=sci_arttext\&pid=S003471672013000100020\&lng=en\&nrm=iso >. Acesso em: 15 abr. 2017.

OLIVEIRA, Maria Liz Cunha. Características dos idosos vítimas de violência doméstica no Distrito Federal. Rev. bras. geriatr. gerontol., Rio de Janeiro, v. 15, n. 3, p. 555-566, Sept. 2012.

OLIVEIRA, Kênnia Stephanie Morais et al. Violência contra idosos: concepções dos profissionais de enfermagem acerca da detecção e prevenção. Rev Gaúcha Enferm. 2018;39:e57462.

ONU BRASIL. A ONU e as pessoas idosas. 2011. Disponível em: <https:/ / goo. gl/6t1Gkh.>. Acesso em: 30 de abr. 2017

Organização Mundial da Saúde. Relatório Mundial Sobre a Prevenção da Violência. 2014. Disponível em:<http:/ / nevusp.org/wp-content/uploads/2015/11/1579-VIPMain-report-Pt-Br-26-10-2015.pdf>. Acesso em: 12 abr. 2017.

PAIVA, Mariana Mapelli de; TAVARES, Darlene Mara dos Santos. Violência física e psicológica contra idosos: prevalência e fatores associados. Rev. Bras. Enferm., Brasília, v. 68, n. 6, p. 1035-1041, Dec. 2015. Disponível em:<http:/ /www.scielo.br/ scielo.php?script=sci_arttext\&pid=S0034-71672015000601035\&lng=en\&nrm=iso $>$. Acesso em: 12 abr. 2017

POLIT, Denise F; Beck, Cheryl Tatano. Using research in evidence-based nursing practice. In: Polit DF, Beck CT, editors. Essentials of nursing research. Methods, appraisal and utilization. Philadelphia : Lippincott Williams \& Wilkins; 2006.

SANCHES, Ana Paula R. Amadio; LEBRAO, Maria Lúcia; DUARTE, Yeda Aparecida de Oliveira. Violência contra idosos: uma questão nova? Saude soc., São Paulo, v. 17, n. 3, p. 90-100, Sept. 2008. Disponível em:<http:/ /www.scielo.br/scielo. php?script=sci_arttext\&pid=S0104-12902008000300010\&lng=en\&nrm=iso $>$. Acesso em: 12 abr. 2017.

SANCHES, Ana Paula R. Amadio. Violência doméstica contra idosos no município de São Paulo. São Paulo. Dissertação [ Mestrado em Saúde Pública]- Faculdade de Saúde Pública; 2006. Disponível em:<http:/ /bases.bireme.br/cgi-bin/wxislind.exe/iah/onli- 
ne / ?IsisScript=iah $/$ iah. $x$ is\&src=google\&base=LILACS\&lang=p\&nextAction=lnk\&exprSearch=444684\&indexSearch=ID>. Acesso em: 09 abr. 2017.

SOUZA, Edinilsa Ramos de; MINAYO, Maria Cecília de Souza. Inserção do tema violência contra a pessoa idosa nas políticas públicas de atenção à saúde no Brasil. Ciênc. saúde coletiva, Rio de Janeiro, v. 15, n. 6, p. 2659-2668, Sept. 2010. Disponível em:http:/ / www.scielo.br/scielo.php?script=sci_arttext\&pid=S1413$81232010000600002 \& \operatorname{lng}=$ en\&nrm=iso > . Acesso em: 15 abr. 2017.

SOUZA, Andréa Santos; MEIRA, Edméia Campos; NERI, Ivone Gonçalves; DA SILVA, Joanice Alves; GONÇALVES, Lucia Hisako Takase. Fatores de risco de maustratos ao idoso na relação idoso/cuidador em convivência familiar. Textos sobre envelhecimento, Rio de Janeiro, v.7, n. 2, 2004.

SPIRDUSO, Waneen Wyrick. Dimensões físicas do envelhecimento. Barueri, SP: Manole, 2005.

WHO. World Health Organization. Missing voices: views of older persons on elder abuse. Geneva: World Health Organization; 2002. Disponível em:<http:/ /www.who. int/ageing/publications/missing_voices/en/>. Acesso em: 12 abr. 2017.

ZIMERMAN, Guite I. Velhice: aspectos biopsicossociais. Porto Alegre: Artes Médicas Sul; 2000. 